\title{
Editorial 67
}

\author{
Eric Scerri ${ }^{1}$
}

Accepted: 20 March 2021 / Published online: 25 March 2021

(C) The Author(s), under exclusive licence to Springer Nature B.V. 2021

The issue before you is the first in volume 23 of the journal, which has been in continuous publication since the year 1999. This particular issue has a distinctly European flavor given that 7 of the 9 full length articles has been provided by authors in different European countries. Here are a few words about each contribution which appear in alphabetical order of the names of first authors.

Miguel Escribano-Cabeza from Spain argues that Leibniz's writings on chemistry have not received enough attention and sets out to remedy this situation. Francesco Di Giacomo from La Sapienza in Rome, Italy, contributes an article on very early chemistry in Plato's Timaeus and indeed suggests that this was the first account of chemical reactions in history.

The next article is by Amihud Gilead a philosopher from Israel, who has been published before in this journal. Here he discusses the meaning of life, no less, from the perspective of generalized crystallography theory and quantum mechanics. Wojciech Grochala is one of Poland's leading chemists with wide and inter-disciplinary interests. His article deals with the color of transition metal compounds and how they can be explained by means of molecular orbital theory.

Eammon Healey is based in Austin, Texas where he specializes in organic chemistry. His contribution highlights the advantages of mechanisms which draw upon single electron transfer, or SET, by contrast to the ubiquitous electron pair mechanisms that one usually encounters in the chemical literature. Peeter Müürsepp and his colleagues from Estonia and Kazakhstan propose a new perspective on the philosophy of science by drawing on the writings of the late Rein Vihalemm, who many of us knew from many international meetings of our society. ${ }^{1}$

Juan Quílez is a chemical educator from Spain whose area of expertise lies in chemical equilibrium. In this, his latest of many articles in Foundations of Chemistry, he considers the history of various derivations of the law of mass action, including those of Horstmann and van't Hoff. The next contribution is from Apostolos Spyropoulos, a molecular

\footnotetext{
1 The next meeting will be conducted remotely and will be organized by Olimpia Lombardi and her colleagues in Buenos Aires, Argentina. Please see the temporary website for the International Society for the Philosophy of Chemistry (ISPC). https://www.researchgate.net/project/24th-conference-of-the-Internatio nal-Society-for-the-Philosophy-of-Chemistry.
}

Eric Scerri

scerri@chem.ucla.edu

1 Department of Chemistry \& Biochemistry, UCLA, Los Angeles, CA 90095, USA 
computation specialist in Greece. His article concerns chemical vagueness and how he regards its relationship to quantum entanglement and emergence.

Hub Zwart, a philosopher from Rotterdam in the Netherlands, is the author of the final article in which he brings together the themes of Marxism, the poetry of Herman Gorter and the influence that the chemist Ida Prins' knowledge of liquid crystals had on Gorter's epic poem. The issue closes with a review of the 2nd edition of Chas McCaw's excellent book entitled, Orbitals with Applications in Atomic Spectra.

Stay safe and I hope to see you remotely at the annual international meeting.

Publisher's Note Springer Nature remains neutral with regard to jurisdictional claims in published maps and institutional affiliations. 